\title{
Graphitic carbon nitride prepared from urea as a photo- catalyst for visible-light carbon dioxide reduction with the aid of a mononuclear ruthenium(II) complex
}

\author{
Kazuhiko Maeda*1, Daehyeon $\mathrm{An}^{1}{ }^{1}$, Ryo Kuriki ${ }^{1,2}$, Daling $\mathrm{Lu}^{3}$ and Osamu Ishitani ${ }^{1}$
}

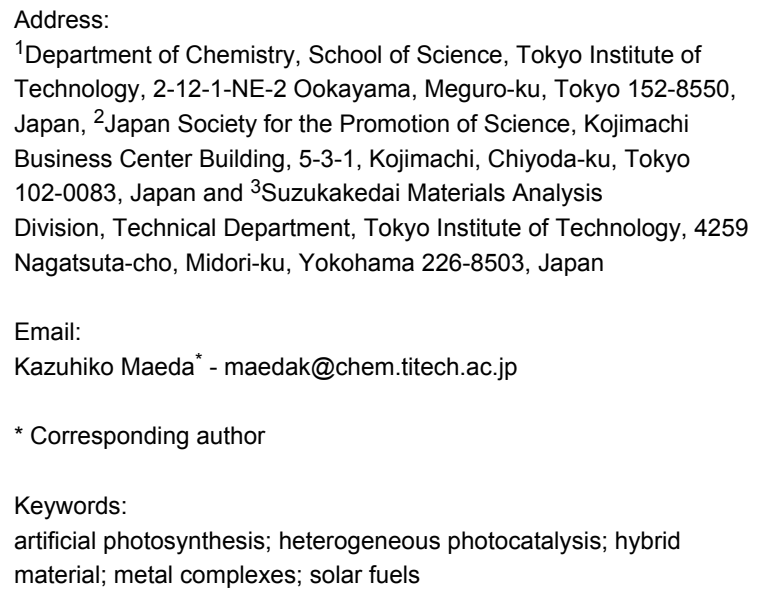

\begin{abstract}
Beilstein J. Org. Chem. 2018, 14, 1806-1812.
\end{abstract}
doi:10.3762/bjoc. 14.153

Received: 21 April 2018

Accepted: 26 June 2018

Published: 17 July 2018

This article is part of the thematic issue "Photoredox catalysis for novel organic reactions".

Guest Editor: M. Antonietti

(c) 2018 Maeda et al.; licensee Beilstein-Institut. License and terms: see end of document.

\begin{abstract}
Graphitic carbon nitride $\left(\mathrm{g}-\mathrm{C}_{3} \mathrm{~N}_{4}\right)$ was synthesized by heating urea at different temperatures (773-923 K) in air, and was examined as a photocatalyst for $\mathrm{CO}_{2}$ reduction. With increasing synthesis temperature, the conversion of urea into g- $\mathrm{C}_{3} \mathrm{~N}_{4}$ was facilitated, as confirmed by X-ray diffraction, FTIR spectroscopy and elemental analysis. The as-synthesized $\mathrm{g}_{-} \mathrm{C}_{3} \mathrm{~N}_{4} \mathrm{samples}_{\text {, further modified }}$ with Ag nanoparticles, were capable of reducing $\mathrm{CO}_{2}$ into formate under visible light $(\lambda>400 \mathrm{~nm})$ in the presence of triethanolamine as an electron donor, with the aid of a molecular $\mathrm{Ru}(\mathrm{II})$ cocatalyst $(\mathrm{RuP})$. The $\mathrm{CO}_{2}$ reduction activity was improved by increasing the synthesis temperature of $\mathrm{g}-\mathrm{C}_{3} \mathrm{~N}_{4}$, with the maximum activity obtained at $873-923 \mathrm{~K}$. This trend was also consistent with that observed in photocatalytic $\mathrm{H}_{2}$ evolution using Pt-loaded g- $\mathrm{C}_{3} \mathrm{~N}_{4}$. The photocatalytic activities of RuP/g- $\mathrm{C}_{3} \mathrm{~N}_{4}$ for $\mathrm{CO}_{2}$ reduction and $\mathrm{H}_{2}$ evolution were thus shown to be strongly associated with the generation of the crystallized g- $\mathrm{C}_{3} \mathrm{~N}_{4}$ phase.
\end{abstract}

\section{Introduction}

Carbon nitride is one of the oldest synthetic polymers [1], and has several allotropes. Among them, graphitic carbon nitride ( $\mathrm{g}-\mathrm{C}_{3} \mathrm{~N}_{4}$ ) is the most stable form and is an emerging material as an organic semiconductor photocatalyst active for various kinds of reactions such as water splitting, $\mathrm{CO}_{2}$ reduction, and degra- dation of harmful organic compounds, because of its non-toxic, stable, and earth-abundant nature [2-7].

Our group has developed photocatalytic $\mathrm{CO}_{2}$ reduction systems using $\mathrm{g}-\mathrm{C}_{3} \mathrm{~N}_{4}$-based materials, in combination with functional 
metal complexes [8-16]. For example, mesoporous g- $\mathrm{C}_{3} \mathrm{~N}_{4}$ (mpg- $\left.\mathrm{C}_{3} \mathrm{~N}_{4}\right)$ modified with a mononuclear $\mathrm{Ru}(\mathrm{II})$ complex, such as trans- $(\mathrm{Cl})-\mathrm{Ru}\left\{\left(\mathrm{PO}_{3} \mathrm{H}_{2}\right)_{2}\right.$ bpy $\left.(\mathrm{CO})_{2} \mathrm{Cl}_{2}\right\}$ (bpy: 2,2'bipyridine), abbreviated as RuP, is capable of photocatalyzing $\mathrm{CO}_{2}$ reduction into formate with high selectivity under visible light irradiation, as confirmed by isotope tracer experiments with ${ }^{13} \mathrm{CO}_{2}$ [8-12]. After the first report of a metal complex/ $\mathrm{C}_{3} \mathrm{~N}_{4}$ hybrid for $\mathrm{CO}_{2}$ reduction, several groups have presented similar reports using cobalt-based metal complexes as reduction cocatalysts [17-20].

In these systems, structural properties of $\mathrm{g}-\mathrm{C}_{3} \mathrm{~N}_{4}$ such as specific surface area and porosity have a strong impact on activity, because they strongly affect the efficiency of electron/hole utilization to the surface chemical reactions [21,22]. Apart from mpg- $\mathrm{C}_{3} \mathrm{~N}_{4}$ that is usually prepared by a hard-template method with multistep procedures [9,23], g- $\mathrm{C}_{3} \mathrm{~N}_{4}$ having a relatively higher surface area can be readily prepared by heating urea, which is an inexpensive and readily available precursor, in air $[14,24]$. In fact, the urea-derived $\mathrm{g}-\mathrm{C}_{3} \mathrm{~N}_{4}$ exhibited an enhanced activity for $\mathrm{CO}_{2}$ reduction compared to mpg- $\mathrm{C}_{3} \mathrm{~N}_{4}$, when modified with $\mathrm{Ag}$ nanoparticles and a binuclear $\mathrm{Ru}(\mathrm{II})$ complex [14].
Thermal heating of urea results in decomposition and formation of $\mathrm{g}-\mathrm{C}_{3} \mathrm{~N}_{4}$, whose physicochemical properties should be dependent on the heating temperature. In this work, we investigated photocatalytic activities of $\mathrm{g}-\mathrm{C}_{3} \mathrm{~N}_{4}$, which was synthesized by heating urea at different temperatures, for visible-light $\mathrm{CO}_{2}$ reduction with the aid of a mononuclear $\mathrm{Ru}$ (II) complex, RuP (see Scheme 1). As mentioned earlier, $g-\mathrm{C}_{3} \mathrm{~N}_{4}$ has been studied as a visible-light-responsive photocatalyst mostly for $\mathrm{H}_{2}$ evolution from aqueous triethanolamine (TEOA) solution $[2,3,5]$. The present work also compares the activities for $\mathrm{CO}_{2}$ reduction with those for $\mathrm{H}_{2}$ evolution in order to obtain a better understanding on photocatalytic activities of $\mathrm{g}-\mathrm{C}_{3} \mathrm{~N}_{4}$ for different kinds of reactions.

\section{Results and Discussion Synthesis of $\mathrm{g}-\mathrm{C}_{3} \mathrm{~N}_{4}$ by thermal heating of urea at different temperatures}

Figure 1 shows XRD patterns of $\mathrm{g}-\mathrm{C}_{3} \mathrm{~N}_{4}$ samples synthesized at different temperatures. Two peaks are observed at 2 theta $=13$ and $27.4^{\circ}$, which are assigned to an in-planar repeating motif and the stacking of the conjugated aromatic system, respectively [25]. This result confirms the successful synthesis of $g-\mathrm{C}_{3} \mathrm{~N}_{4}$

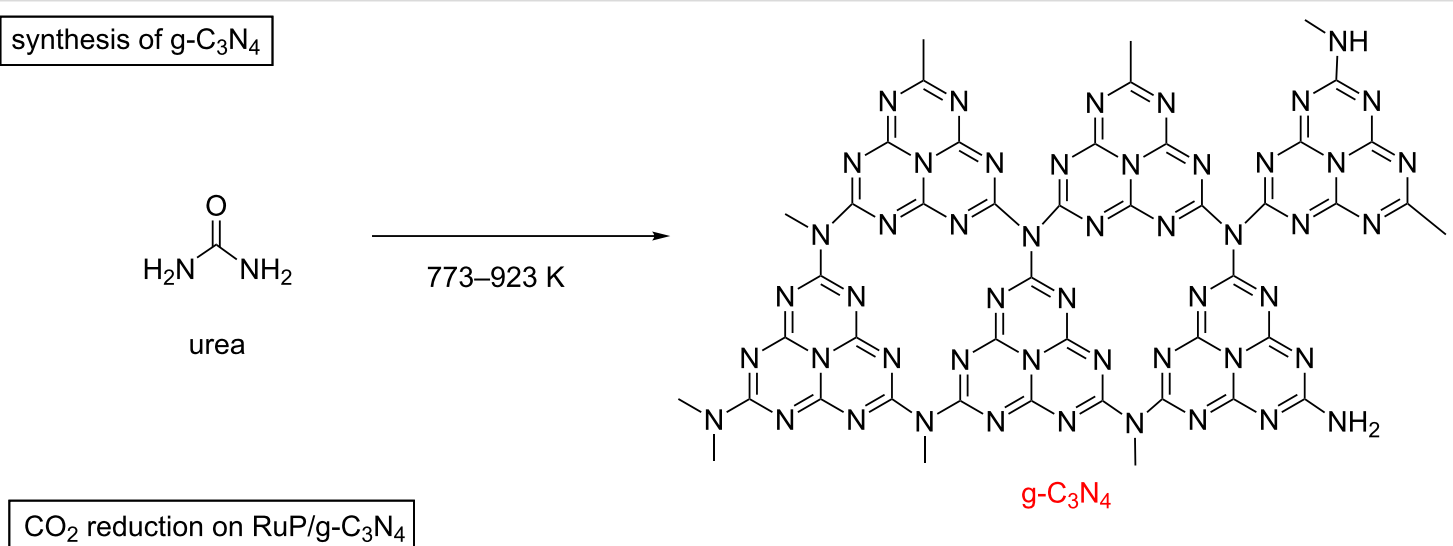

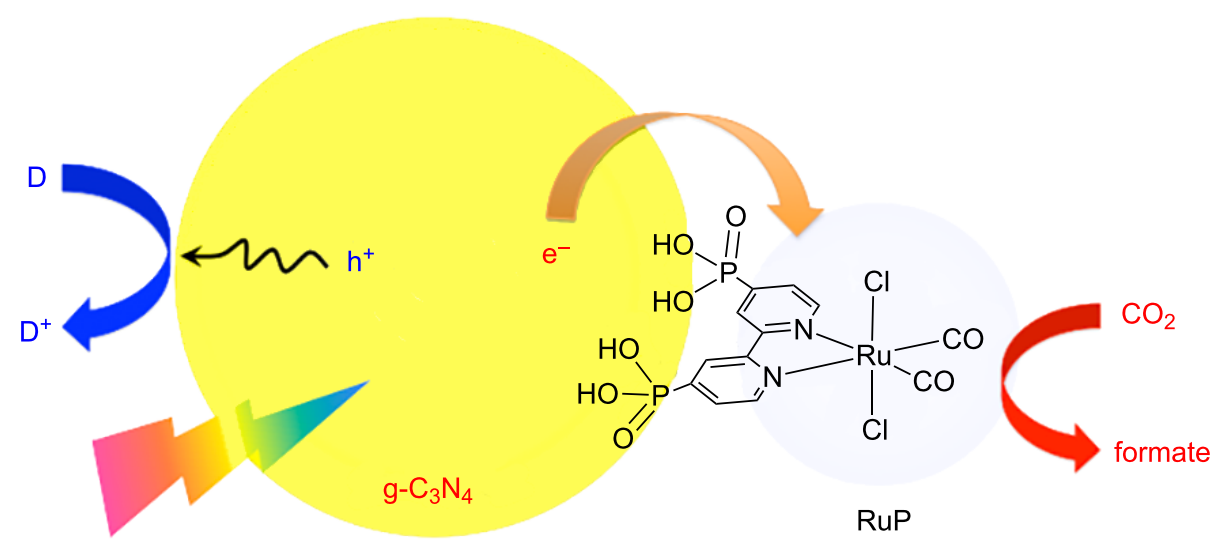

visible light 
at the present temperature range examined. With increasing temperature, the intensity of these peaks became stronger, indicating that the formation of $\mathrm{g}-\mathrm{C}_{3} \mathrm{~N}_{4}$ was facilitated at higher temperatures. It is, however, noted that the high-temperature heating also caused the loss of the product mass due to the decomposition of $\mathrm{g}-\mathrm{C}_{3} \mathrm{~N}_{4}$ itself [25].

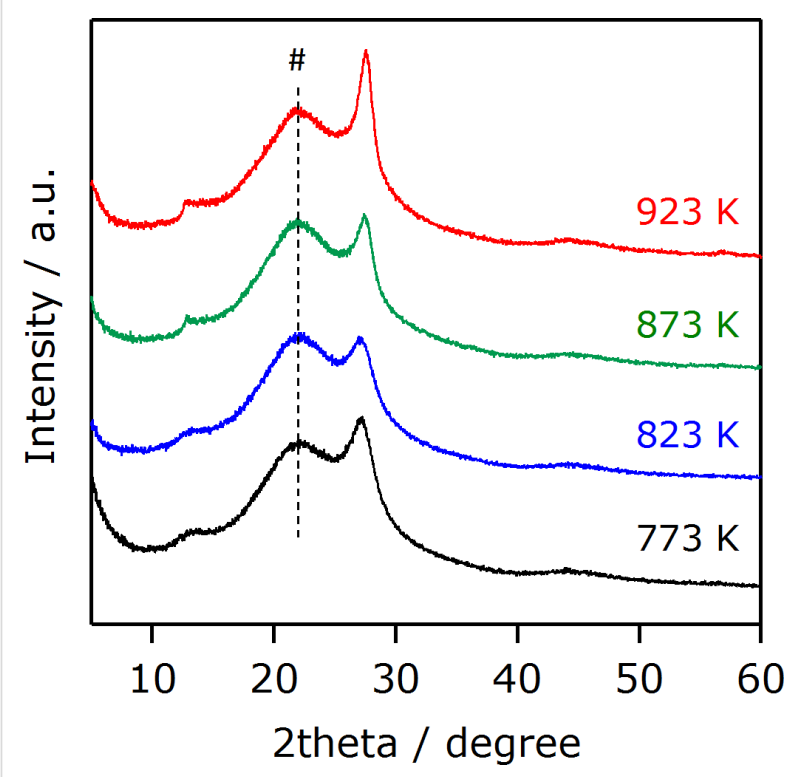

Figure 1: XRD patterns of $\mathrm{g}-\mathrm{C}_{3} \mathrm{~N}_{4}$ synthesized at different temperatures. A broad peak at around 22 degree, indicated by \#, in XRD patterns originated from a glass folder for the measurement.

FTIR spectra for the same set of the samples are shown in Figure 2. Characteristic peaks can be seen in the $1650-1200 \mathrm{~cm}^{-1}$ region. The peaks at 1322 and $1243 \mathrm{~cm}^{-1}$ are assigned to the stretching vibration of connected units of $\mathrm{C}-\mathrm{N}(-\mathrm{C})-\mathrm{C}$ (full condensation) or $\mathrm{C}-\mathrm{NH}-\mathrm{C}$ (partial condensation) $[26,27]$. The leftovers of $1641,1569,1462$ and $1412 \mathrm{~cm}^{-1}$ are assigned to stretching vibration modes of heptazine-derived repeating units, and are sharper with increasing temperature. This further indicates the production of $\mathrm{g}-\mathrm{C}_{3} \mathrm{~N}_{4}$ at elevated temperatures, consistent with the XRD analysis (Figure 1). The
$812 \mathrm{~cm}^{-1}$ peak is attributed to the out-of-plane bending vibration characteristic of heptazine rings.

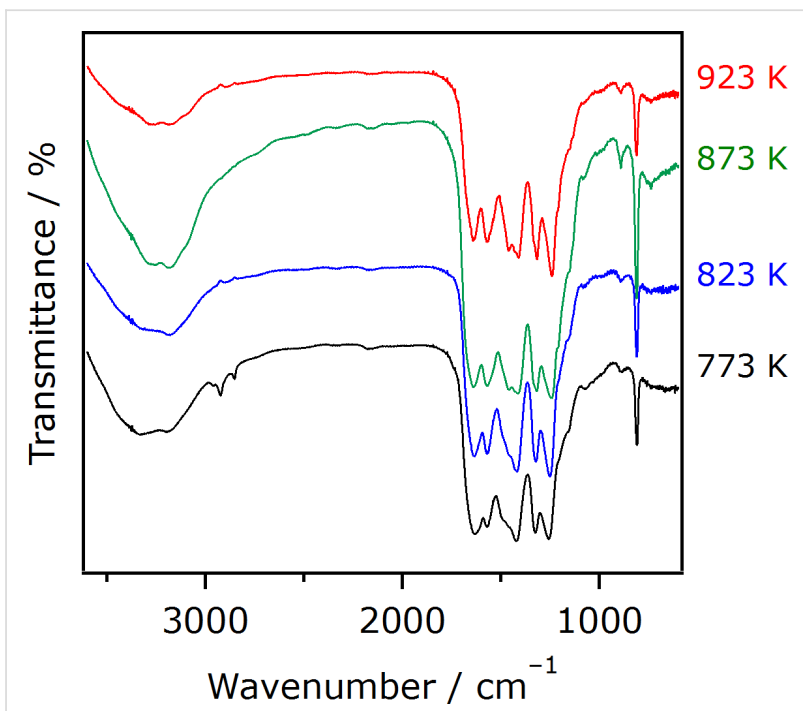

Figure 2: FTIR spectra of $\mathrm{g}-\mathrm{C}_{3} \mathrm{~N}_{4}$ synthesized at different temperatures. Each spectrum was acquired by a $\mathrm{KBr}$ method in $\mathrm{N}_{2}$ atmosphere.

The results of elemental analyses for the as-prepared $g-\mathrm{C}_{3} \mathrm{~N}_{4}$ samples were listed in Table 1 . In all cases, not only carbon and nitrogen, which are the main constituent elements of $\mathrm{g}-\mathrm{C}_{3} \mathrm{~N}_{4}$, but also hydrogen and oxygen were detected. As the synthesis temperature increased, the compositions of carbon and nitrogen became closer to the ideal values, although the carbon content was obviously lower. The hydrogen and oxygen impurities were also reduced with an increase in the synthesis temperature. These results indicate that rising temperature is important to obtain purer $\mathrm{g}-\mathrm{C}_{3} \mathrm{~N}_{4}$ in terms of the chemical composition.

TEM images of the same samples are shown in Figure 3. The sample synthesized at $773 \mathrm{~K}$ had a lot of circular voids having $50-100 \mathrm{~nm}$ in size. At $823 \mathrm{~K}$, this void structure was less prominent, and sheet-like morphology started to appear. With a further increase in the synthesis temperature, the synthesized samples consisted of disordered nanosheets. This change in par-

\begin{tabular}{|c|c|c|c|c|c|}
\hline \multirow[t]{2}{*}{ synthesis temperature $[\mathrm{K}]$} & \multicolumn{4}{|c|}{ composition [wt \%] } & \multirow[t]{2}{*}{ specific surface area $\left[\mathrm{m}^{2} \mathrm{~g}^{-1}\right]$} \\
\hline & C & $\mathrm{N}$ & $\mathrm{H}$ & $\mathrm{O}$ & \\
\hline 773 & 32.68 & 59.60 & 1.78 & 4.98 & 38 \\
\hline 823 & 33.29 & 59.97 & 1.53 & 4.58 & 36 \\
\hline 873 & 33.64 & 60.38 & 1.26 & 4.15 & 56 \\
\hline 923 & 34.29 & 61.14 & 1.09 & 2.90 & 54 \\
\hline ideal $\mathrm{C}_{3} \mathrm{~N}_{4}$ & 39.13 & 60.87 & 0 & 0 & - \\
\hline
\end{tabular}



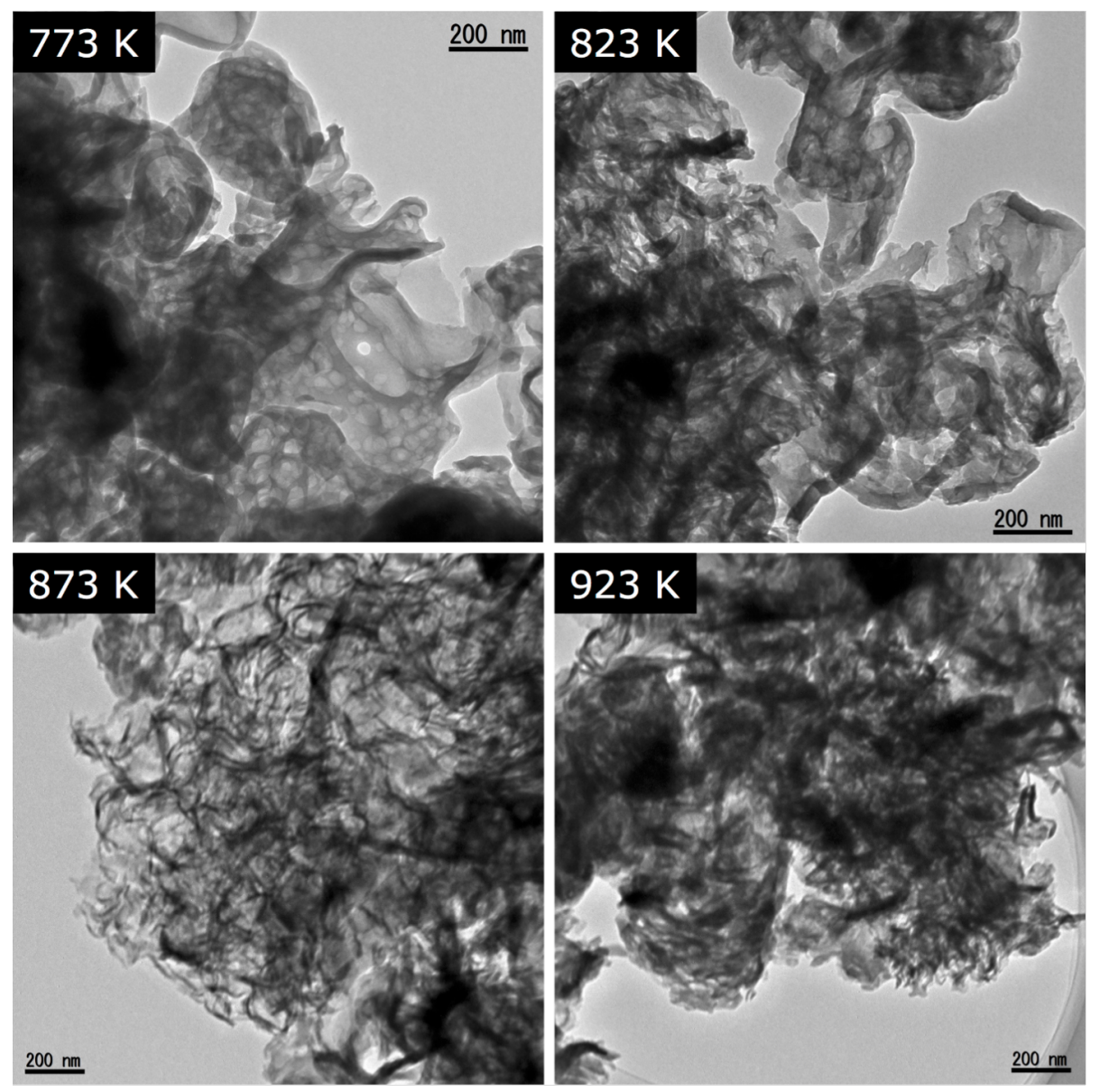

Figure 3: TEM images of $\mathrm{g}-\mathrm{C}_{3} \mathrm{~N}_{4}$ synthesized at different temperatures.

ticle morphology is in qualitative agreement with that in the specific surface area (see Table 1).

Figure 4 shows the UV-visible diffuse reflectance spectra of g- $\mathrm{C}_{3} \mathrm{~N}_{4}$ synthesized at different temperatures. All of the samples exhibited an absorption edge at $420-450 \mathrm{~nm}$, attributed to electron transitions from the valence band formed by nitrogen $2 \mathrm{p}$ orbitals to the conduction band formed by carbon $2 \mathrm{p}$ orbitals [25]. The band gaps of the synthesized $g-\mathrm{C}_{3} \mathrm{~N}_{4}$ were estimated to be ca. 2.8-3.0 eV, from the onset wavelength of the diffuse reflectance spectra. This value is consistent with that reported previously [24]. As the synthesis temperature increases, the onset wavelength is shifted to longer wavelengths (i.e., band gap is decreased), with more pronounced tailing absorption extending to $550 \mathrm{~nm}$ that is assigned to $\mathrm{n}-\pi^{*}$ transitions involving lone pairs on the edge nitrogen atoms of the heptazine rings $[28,29]$. While the $n-\pi^{*}$ transitions are forbidden for perfectly symmetric and planar heptazine units, they become partially allowed with increasing the condensation of layers in $g-\mathrm{C}_{3} \mathrm{~N}_{4}$, which results from an increase in the synthesis temperature.

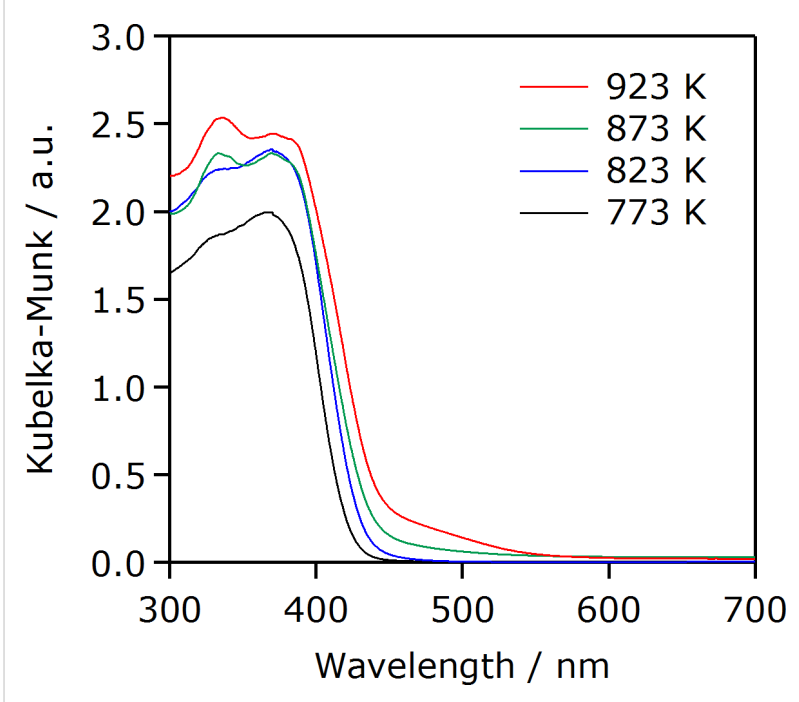

Figure 4: UV-visible diffuse reflectance spectra of $\mathrm{g}-\mathrm{C}_{3} \mathrm{~N}_{4}$ synthesized at different temperatures. 


\section{Photocatalytic activities for $\mathrm{CO}_{2}$ reduction and $\mathrm{H}_{2}$ evolution}

Using the as-prepared $\mathrm{g}_{-} \mathrm{C}_{3} \mathrm{~N}_{4}, \mathrm{CO}_{2}$ reduction was conducted with the aid of RuP cocatalyst and Ag promoter in a $N, N$ dimethylacetamide (DMA)/TEOA mixed solution under visible light $(\lambda>400 \mathrm{~nm})$. Here TEOA works as an effective electron donor that scavenges holes generated in the valence band of g- $\mathrm{C}_{3} \mathrm{~N}_{4}$ [25]. The use of DMA as the solvent for $\mathrm{CO}_{2}$ reduction using RuP/mpg- $\mathrm{C}_{3} \mathrm{~N}_{4}$ has previously been shown to be the best choice of solvents to maximize the photocatalytic activity [10] Because RuP does not absorb visible light efficiently, the g- $\mathrm{C}_{3} \mathrm{~N}_{4}$ component can be activated selectively by visible light [10]. Our previous study also indicated that the amount of a molecular cocatalyst is very important in this kind of mononuclearcomplex $/ \mathrm{C}_{3} \mathrm{~N}_{4}$ hybrid photocatalyst for visible-light $\mathrm{CO}_{2}$ reduction [8]. To eliminate any other effects other than heating temperature of urea, we fixed the amount of RuP in this study. Ag nanoparticles loaded on mpg- $\mathrm{C}_{3} \mathrm{~N}_{4}$ serves as a promoter of electron transfer from mpg- $\mathrm{C}_{3} \mathrm{~N}_{4}$ to RuP, as discussed in our previous work [13]. TEM observation indicated that the loaded $\mathrm{Ag}$ is in the form of nanoparticles of 5-10 nm in size (Figure 5). Without $\mathrm{Ag}$ (i.e., $\mathrm{RuP} / \mathrm{g}-\mathrm{C}_{3} \mathrm{~N}_{4}$ ), formate production was clearly observable, but the activity was typically $20 \%$ that of $\mathrm{RuP} / \mathrm{Ag} / \mathrm{g}-\mathrm{C}_{3} \mathrm{~N}_{4}$. Hence we employed $\mathrm{Ag}$ as an additional promoter in all cases. It should be also noted that no reaction took place using only $\mathrm{g}_{-} \mathrm{C}_{3} \mathrm{~N}_{4}$.

As listed in Table 2, the main product during the reaction was formate with $90-95 \%$ selectivity. Minor products were $\mathrm{CO}$ and $\mathrm{H}_{2}$. With increasing the synthesis temperature, the formate generation activity was improved to reach a maximum at $873-923 \mathrm{~K}$, while almost unchanging the $\mathrm{CO}$ and $\mathrm{H}_{2}$ evolution. The catalytic turnover number of formate generation calculated based on the mole amount of RuP at the optimal conditions reached 650 , which confirms the catalytic cycle of the reaction.

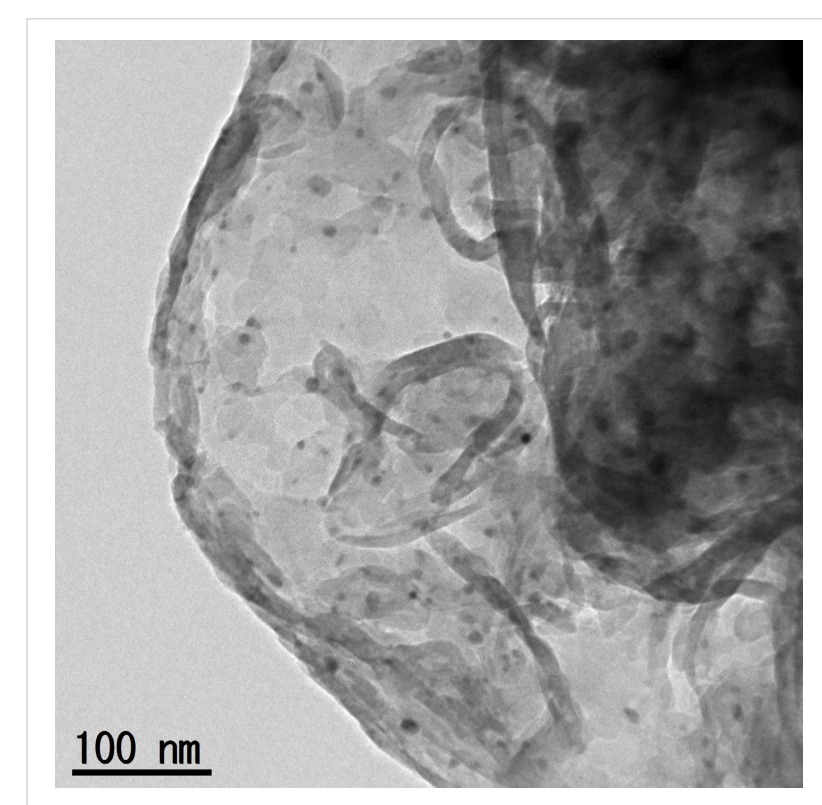

Figure 5: A typical TEM image of Ag-loaded $g-\mathrm{C}_{3} \mathrm{~N}_{4}$. The synthesis temperature of $\mathrm{g}-\mathrm{C}_{3} \mathrm{~N}_{4}$ was $873 \mathrm{~K}$ in this case.

$\mathrm{H}_{2}$ evolution was also conducted in a mixed solution of water and TEOA. It is also noted that Pt was in situ loaded on $\mathrm{g}-\mathrm{C}_{3} \mathrm{~N}_{4}$ as a cocatalyst to facilitate $\mathrm{H}_{2}$ evolution. As listed in Table 2, all of the synthesized samples produced $\mathrm{H}_{2}$. Similar to the trend in $\mathrm{CO}_{2}$ reduction, the $\mathrm{H}_{2}$ evolution activity was enhanced as the synthesis temperature was increased.

The results of the photocatalytic reactions thus indicated that photocatalytic activities of $\mathrm{g}-\mathrm{C}_{3} \mathrm{~N}_{4}$ derived from urea were dependent on the heating temperature of urea. The trend of activity observed in both $\mathrm{CO}_{2}$ reduction and $\mathrm{H}_{2}$ evolution could be explained in terms of the formation of the $\mathrm{g}-\mathrm{C}_{3} \mathrm{~N}_{4}$ structure. Physicochemical analyses indicated that increasing the synthesis temperature of $\mathrm{g}-\mathrm{C}_{3} \mathrm{~N}_{4}$ promotes conversion of urea into g- $\mathrm{C}_{3} \mathrm{~N}_{4}$ (Figure 1 and Figure 2), which has even better visible-

Table 2: Photocatalytic activities of $\mathrm{g}-\mathrm{C}_{3} \mathrm{~N}_{4}$ synthesized at different temperatures for $\mathrm{CO}_{2}$ reduction and $\mathrm{H}_{2}$ evolution under visible light $(\lambda>400 \text { nm })^{\mathrm{a}}$.

synthesis temperature $[\mathrm{K}]$

\begin{tabular}{lcccc}
\cline { 2 - 3 } & formate & $\mathrm{CO}$ & $\mathrm{H}_{2}$ & \\
773 & 2.8 & 0.2 & 0.1 & 7.0 \\
823 & 3.0 & 0.2 & 0.1 & 9.7 \\
873 & 5.2 & 0.1 & 0.1 & 17.9 \\
923 & 5.1 & 0.1 & 0.1 & 18.6 \\
\hline
\end{tabular}

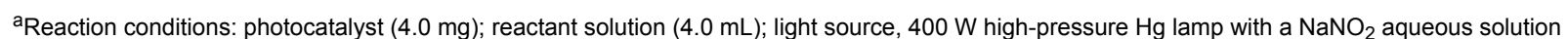
filter. Reaction time: $5 \mathrm{~h}$. bWith $2.0 \mu \mathrm{mol} \mathrm{g}{ }^{-1} \mathrm{RuP}$ and $5.0 \mathrm{wt} \% \mathrm{Ag}$. Performed in a DMA/TEOA mixed solution (4:1 v/v). ${ }^{\mathrm{C} W i t h} 3.0 \mathrm{wt} \% \mathrm{Pt}$. Performed in a water/TEOA mixed solution $(9: 1 \mathrm{v} / \mathrm{v})$. 
light absorption (Figure 4). The better light absorption profile as well as higher specific surface area of the $\mathrm{g}_{-} \mathrm{C}_{3} \mathrm{~N}_{4}$ samples synthesized at elevated temperatures would have a positive impact on the activity to a certain extent. It is also noted that the photocatalytic activity for $\mathrm{CO}_{2}$ reduction was much lower than that for $\mathrm{H}_{2}$ evolution, even though the same electron donor, TEOA, was employed. This in turn implies that there still remains much room for the improvement of $\mathrm{CO}_{2}$ reduction activity, for example, if a proper modification method, which allows for more efficient electron transfer, is developed. This is now under investigation in our laboratory.

\section{Conclusion}

Heating urea in air at 773-923 $\mathrm{K}$ resulted in the formation of g- $\mathrm{C}_{3} \mathrm{~N}_{4}$, which exhibited photocatalytic activity for $\mathrm{CO}_{2}$ reduction into formate under visible light with the aid of a molecular Ru(II) cocatalyst. Experimental results highlighted that higher heating temperature for the synthesis led to the production of more crystallized $\mathrm{g}-\mathrm{C}_{3} \mathrm{~N}_{4}$ with higher specific surface area and more pronounced visible-light absorption, which was preferable for photocatalytic reactions of both $\mathrm{CO}_{2}$ reduction and $\mathrm{H}_{2}$ evolution. However, too high synthesis temperature causes a mass loss of $\mathrm{g}-\mathrm{C}_{3} \mathrm{~N}_{4}$ due to thermal decomposition, which is not practically desirable.

\section{Experimental}

\section{Materials and reagents}

g- $\mathrm{C}_{3} \mathrm{~N}_{4}$ samples were synthesized by heating $10 \mathrm{~g}$ of urea $\left(99^{+} \%\right.$, Wako Chemicals Co.) in air at a ramp rate of $2.3 \mathrm{~K} \mathrm{~min}^{-1}$ to a given temperature (773-923 K), keeping that temperature for $4 \mathrm{~h}$, then cooling without temperature control.

Ag (5.0 wt \%) was loaded as a promoter onto the surface of g- $\mathrm{C}_{3} \mathrm{~N}_{4}$ by an impregnation method using $\mathrm{AgNO}_{3}(>99.8 \%$, Wako Pure Chemicals Co.) as the precursor according to the previous method [13]. $\mathrm{g}-\mathrm{C}_{3} \mathrm{~N}_{4}(50 \mathrm{mg})$ was dispersed in an aqueous $\mathrm{AgNO}_{3}$ solution $(10 \mathrm{~mL})$. The water content was subsequently removed under reduced pressure at $317 \mathrm{~K}$. The resulting solid sample was heated under a $\mathrm{H}_{2}$ stream $\left(20 \mathrm{~mL} \min ^{-1}\right)$ at $473 \mathrm{~K}$ for $1 \mathrm{~h}$.

RuP was synthesized according to methods reported in our previous paper [10]. Adsorption of $\mathrm{RuP}$ onto $\mathrm{Ag} / \mathrm{g}-\mathrm{C}_{3} \mathrm{~N}_{4}$ was conducted by dispersing $40 \mathrm{mg}$ of $\mathrm{Ag} / \mathrm{g}-\mathrm{C}_{3} \mathrm{~N}_{4}$ in an acetonitrile $(\mathrm{MeCN})$ solution $(20 \mathrm{~mL})$ of RuP. The suspension was stirred overnight at room temperature in the dark to allow for the adsorption/desorption equilibrium, followed by filtration and washing with acetonitrile. The filtrates were collected and concentrated to a volume of $30 \mathrm{~mL}$. The amount of the ruthenium complex absorbed was calculated based on the UV-vis spectrum of the filtrate, using Equation 1: adsorbed amount $\left(\mathrm{mol} \mathrm{g}^{-1}\right)=$

$$
\frac{A_{\text {before }}-A_{\text {after }}}{A_{\text {before }}} \cdot \frac{C\left(\mathrm{~mol} \mathrm{~L}^{-1}\right) \times 20 \times 10^{-3}(\mathrm{~L})}{40 \times 10^{-3}(\mathrm{~g})}
$$

where $A_{\text {before }}$ and $A_{\text {after }}$ are the absorbance of the solution before and after the adsorption procedure, respectively, and $C$ is the initial concentration of RuP.

Organic solvents used in this work were subject to purification prior to use. DMA was dried over molecular sieves $4 \AA$ (which was heated at $373 \mathrm{~K}$ under reduced pressure $(<1$ Torr) overnight for several days), and distilled under reduced pressure (10-20 Torr). $\mathrm{MeCN}$ was distilled over $\mathrm{P}_{2} \mathrm{O}_{5}$ twice, and then distilled over $\mathrm{CaH}_{2}$ prior to use. TEOA was distilled under reduced pressure $(<1$ Torr). The distilled DMA and TEOA were kept under Ar prior to use.

\section{Characterization}

The prepared materials were characterized by X-ray diffraction (XRD) (MiniFlex600, Rigaku; $\mathrm{Cu} \mathrm{K} \alpha$ radiation), Fourier-transform infrared (FTIR) spectroscopy (FTIR-610, Jasco), transmission electron microscopy (TEM) (JEM-2010F, JEOL), and UV-visible diffuse reflectance spectroscopy (DRS) (V-565, Jasco). The Brunauer-Emmett-Teller (BET) surface area of each specimen was determined using a BELSOEP-mini instrument (BEL Japan) at liquid nitrogen temperature. The amount of carbon, nitrogen, hydrogen and oxygen were determined by elemental analysis (MICRO CORDER JM10, J-SCIENCE) by Suzukakedai Materials Analysis Division, Technical Department, Tokyo Institute of Technology.

\section{Photocatalytic reactions}

Reactions were performed at room temperature (298 K) using an $8 \mathrm{~mL}$ test tube containing $4 \mathrm{~mL}$ of solution by dispersing $4 \mathrm{mg}$ of photocatalyst powder. For $\mathrm{H}_{2}$ evolution, a mixed solution of water and TEOA $(9: 1 \mathrm{v} / \mathrm{v})$ was used as the reactant solution, which was in prior purged with Ar for 20-30 min to remove residual air. Pt (3.0 wt \%) was loaded in situ using $\mathrm{H}_{2} \mathrm{PtCl}_{6}(>98.5 \%$, Wako Pure Chemicals Co.) as the precursor. For $\mathrm{CO}_{2}$ reduction, a mixed solution of DMA and TEOA $(4: 1 \mathrm{v} / \mathrm{v})$ was used. Prior to irradiation, the suspension was purged with $\mathrm{CO}_{2}$ (Taiyo Nippon Sanso Co., >99.995\%) for 20-30 min. A $400 \mathrm{~W}$ high-pressure $\mathrm{Hg}$ lamp (SEN) was used as a light source, in combination with a $\mathrm{NaNO}_{2}$ solution as a filter to provide visible light irradiation $(\lambda>400 \mathrm{~nm})$. The gaseous reaction products were analyzed using a gas chromatograph with a thermal conductivity detector (GL Science, Model GC323). The formate generated in the liquid phase was 
analyzed via a capillary electrophoresis system (Otsuka Electronics Co., Model CAPI-3300).

\section{Acknowledgements}

This work was supported by a Grant-in-Aid for Young Scientists (A) (Project JP16H06130) from JSPS. It was also partially supported by a Grant-in-Aid for Scientific Research on Innovative Area "Mixed Anion (Project JP16H06441)" and a CREST program (Project JPMJCR13L1) (JST). K.M. acknowledges The Noguchi Institute and Murata Research Foundation financial support. R.K. wishes to acknowledge support by a JSPS Fellowship for Young Scientists (Project JP17J03705).

\section{ORCID ${ }^{\circledR} \mathrm{iDs}$}

Kazuhiko Maeda - https://orcid.org/0000-0001-7245-8318

Ryo Kuriki - https://orcid.org/0000-0002-3843-2867

Daling Lu - https://orcid.org/0000-0002-9084-480X

Osamu Ishitani - https://orcid.org/0000-0001-9557-7854

\section{References}

1. Liebig, J. Ann. Pharm. (Lemgo, Ger.) 1834, 10, 1-47. doi:10.1002/jlac.18340100102

2. Wang, Y.; Wang, X.; Antonietti, M. Angew. Chem., Int. Ed. 2012, 51, 68-89. doi:10.1002/anie.201101182

3. Zheng, Y.; Lin, L.; Wang, B.; Wang, X. Angew. Chem., Int. Ed. 2015, 54, 12868-12884. doi:10.1002/anie.201501788

4. Zhang, J.; Chen, Y.; Wang, X. Energy Environ. Sci. 2015, 8, 3092-3108. doi:10.1039/C5EE01895A

5. Kuriki, R.; Maeda, K. Phys. Chem. Chem. Phys. 2017, 19, 4938-4950. doi:10.1039/C6CP07973C

6. Yin, S.; Han, J.; Zhou, T.; Xu, R. Catal. Sci. Technol. 2015, 5, 5048-5061. doi:10.1039/C5CY00938C

7. Fang, Y.; Wang, X. Chem. Commun. 2018, 54, 5674-5687. doi:10.1039/C8CC02046A

8. Maeda, K.; Sekizawa, K.; Ishitani, O. Chem. Commun. 2013, 49, 10127-10129. doi:10.1039/c3cc45532g

9. Maeda, K.; Kuriki, R.; Zhang, X.; Wang, X.; Ishitani, O. J. Mater. Chem. A 2014, 2, 15146-15151. doi:10.1039/C4TA03128H

10. Kuriki, R.; Sekizawa, K.; Ishitani, O.; Maeda, K. Angew. Chem., Int. Ed. 2015, 54, 2406-2409. doi:10.1002/anie.201411170

11. Kuriki, R.; Ishitani, O.; Maeda, K. ACS Appl. Mater. Interfaces 2016, 8 , 6011-6018. doi:10.1021/acsami.5b11836

12. Maeda, K.; Kuriki, R.; Ishitani, O. Chem. Lett. 2016, 45, 182-184. doi:10.1246/cl.151061

13. Kuriki, R.; Matsunaga, H.; Nakashima, T.; Wada, K.; Yamakata, A.; Ishitani, O.; Maeda, K. J. Am. Chem. Soc. 2016, 138, 5159-5170. doi:10.1021/jacs.6b01997

14. Kuriki, R.; Yamamoto, M.; Higuchi, K.; Yamamoto, Y.; Akatsuka, M.; Lu, D.; Yagi, S.; Yoshida, T.; Ishitani, O.; Maeda, K. Angew. Chem., Int. Ed. 2017, 56, 4867-4871. doi:10.1002/anie.201701627

15. Wada, K.; Eguchi, M.; Ishitani, O.; Maeda, K. ChemSusChem 2017, 10, 287-295. doi:10.1002/cssc.201600661

16. Wada, K.; Ranasinghe, C. S. K.; Kuriki, R.; Yamakata, A.; Ishitani, O.; Maeda, K. ACS Appl. Mater. Interfaces 2017, 9, 23869-23877. doi:10.1021/acsami.7b07484
17. Lin, J.; Pan, Z.; Wang, X. ACS Sustainable Chem. Eng. 2014, 2, 353-358. doi:10.1021/sc4004295

18. Wang, S.; Lin, J.; Wang, X. Phys. Chem. Chem. Phys. 2014, 16, 14656-14660. doi:10.1039/c4cp02173h

19. Walsh, J. J.; Jiang, C.; Tang, J.; Cowan, A. J. Phys. Chem. Chem. Phys. 2016, 18, 24825-24829. doi:10.1039/C6CP04525A

20. Zhao, G.; Pang, H.; Liu, G.; Li, P.; Liu, H.; Zhang, H.; Shi, L.; Ye, J. Appl. Catal., B: Environ. 2017, 200, 141-149. doi:10.1016/j.apcatb.2016.06.074

21. Maeda, K. J. Photochem. Photobiol., C 2011, 12, 237-268. doi:10.1016/j.jphotochemrev.2011.07.001

22. Maeda, K.; Domen, K. Bull. Chem. Soc. Jpn. 2016, 89, 627-648. doi:10.1246/bcsj.20150441

23. Goettmann, F.; Fischer, A.; Antonietti, M.; Thomas, A. Angew. Chem., Int. Ed. 2006, 45, 4467-4471. doi:10.1002/anie.200600412

24. Liu, J.; Zhang, T.; Wang, Z.; Dawson, G.; Chen, W. J. Mater. Chem. 2011, 21, 14398-14401. doi:10.1039/c1jm12620b

25. Wang, X.; Maeda, K.; Thomas, A.; Takanabe, K.; Xin, G.; Carlsson, J. M.; Domen, K.; Antonietti, M. Nat. Mater. 2009, 8, 76-80. doi:10.1038/nmat2317

26. Lotsch, B. V.; Döblinger, M.; Sehnert, J.; Seyfarth, L.; Senker, J.; Oeckler, O.; Schnick, W. Chem. - Eur. J. 2007, 13, 4969-4980. doi:10.1002/chem.200601759

27. Bojdys, M. J.; Müller, J.-O.; Antonietti, M.; Thomas, A. Chem. - Eur. J. 2008, 14, 8177-8182. doi:10.1002/chem.200800190

28. Jorge, A. B.; Martin, D. J.; Dhanoa, M. T. S.; Rahman, A. S.; Makwana, N.; Tang, J.; Sella, A.; Corà, F.; Firth, S.; Darr, J. A.; McMillan, P. F. J. Phys. Chem. C 2013, 117, 7178-7185. doi:10.1021/jp4009338

29. Zhang, H.; Yu, A. J. Phys. Chem. C 2014, 118, 11628-11635. doi:10.1021/jp503477x

\section{License and Terms}

This is an Open Access article under the terms of the Creative Commons Attribution License (http://creativecommons.org/licenses/by/4.0). Please note that the reuse, redistribution and reproduction in particular requires that the authors and source are credited.

The license is subject to the Beilstein Journal of Organic Chemistry terms and conditions: (https://www.beilstein-journals.org/bjoc)

The definitive version of this article is the electronic one which can be found at: $\underline{\text { doi: } 10.3762 / \text { bjoc. } 14.153}$ 